\title{
Experimental and numerical investigations on full-scale adhesively bonded timber trusses
}

\author{
Till Vallée • Thomas Tannert • Simon Hehl
}

Received: 21 July 2010/Accepted: 24 March 2011/Published online: 7 April 2011

(C) RILEM 2011

\begin{abstract}
Timber architecture, taking advantage of modern production techniques, is increasingly moving towards free forms; however, traditional joining techniques are not yet adapted to echo the new expression at the level of the details. This paper reports on adhesively bonded joints as a way to help architects fully unleash their creative potential. For this purpose, experimental and numerical investigations on full-scale adhesively bonded timber trusses were performed, in which adhesive bonds were compared to traditional doweled connections. The adhesively bonded trusses achieved significantly higher failure load and stiffness. Tests on small clear specimens were conducted to determine input parameters for finite element analyses. The sole timber connection was characterised, giving valuable insights into the mechanical behaviour of this truss component. At this end, the influence of the embedded length of the applied sleet plates was experimentally
\end{abstract}

T. Vallée $(\square)$

College of Architecture and Engineering, University

of Applied Sciences, Fribourg, Switzerland

e-mail: till.vallee@fibreworks.org

T. Tannert

Department of Wood Science, University of British

Columbia, Vancouver, BC, Canada

S. Hehl

Timber and Composite Construction, Bern University of Applied Sciences, Biel, Switzerland determined, delivering data to benchmark the subsequent dimensioning method. The trusses were then modeled and excellent agreement was found between numerical and experimental results. Finally, a dimensioning method, based on a realistic multi-axial failure criterion coupled with size effects was implemented and yielded very good agreement when with experimental results. The reported investigation demonstrates the high potential of adhesive bonding in timber structures.

Keywords Timber construction - Truss structures · Adhesive bonding $\cdot$ Bearing capacity $\cdot$ Size effect . Probabilistic method

\section{Introduction}

Modern timber architecture, probably best illustrated by Shigeru Ban [1], is increasingly moving towards free forms, for which currently used timber joining methods do not offer adapted solutions. As an example, new concepts, including folded structures derived from the Japanese art of Origami, were developed [2, 3]. The results, although impressive in the overall architectural expression, clearly indicate that the "new architecture" has not yet diffused to all structural levels; i.e. connections are still achieved by traditional structural joints, as shown in Fig. 1, which arguably weakens the expression. Adhesively bonded joints clearly can help 


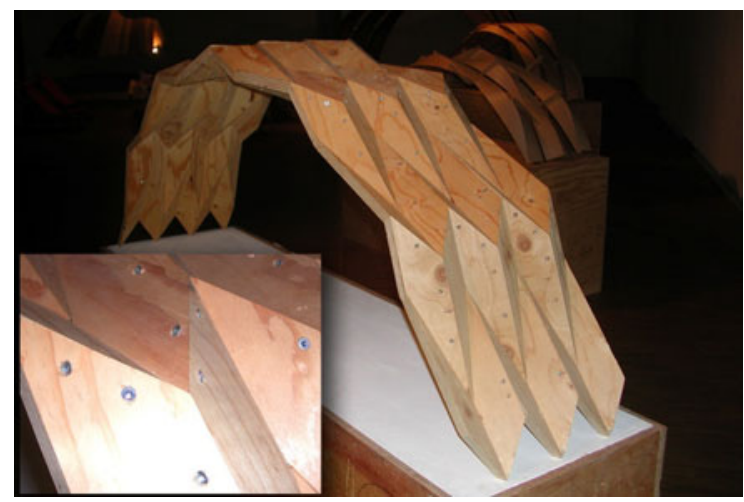

Fig. 1 Example of innovative timber architecture with nonadapted joints

to overcome this substitution phase, so commonly encountered in structural engineering, when new materials or structural concepts were introduced [4, 5].

Adhesively bonded joints usually exhibit higher capacities than connections with dowel type mechanical fasteners, but also higher stiffness, the latter being of particular importance when the governing factor is serviceability limit state, as is it often the case with timber structures [6]. Adhesive bonding can provide an efficient and durable method provided that: (i) the joints are correctly designed using an appropriate approach; (ii) suitable materials and specifications are adopted; (iii) the work is undertaken by experienced operatives; and (iv) strict quality control is exercised [7].

The many advantages of adhesively bonded joints were first recognized by the airplane industry: attractive strength-to-weight ratio, large stress-bearing area, excellent fatigue strength, sealing of joints against the environment, etc. One of the most prominent early examples was the "de Havilland Mosquito" aircraft which essentially consisted of plywood and substantial parts being glued together [8].

Timber trusses as a structural system emerged from the classical timber framing in the Mediterranean region. Truss construction has always been associated with the high end of carpentry; up to the middle of the 19th century, trusses were used predominantly in prestigious public buildings such as temples, churches, or bridges. While there is only a small body of evidence for trussed roofs of antiquity [9], there are abundant examples of long-span roof systems from the Middle Ages through the Renaissance [10] and a myriad of truss forms developed [11]. It is only during the last two centuries, that trusses became shaped by engineering analysis and design $[12,13]$. Since the middle of the 20th century, trusses as system for long spans were increasingly replaced by more cost-effective glulam systems where less effort is put into the connections. As an answer to this challenge, a shift in the joining technique for trusses has occurred, e.g. replacing mortise-and-tenon joints with nailed steel plates or doweled connections [14]. Such connections however, significantly reduce the stiffness of timber structures, since large deformations are required to fully activate them [15]. The advantages of bonded trusses have just recently been presented by Poutanen and Ovazza [16] in an experimental study showing that combining the structural advantages to the architectural ones can lead to attractive solutions and potential economical benefit. The truss exhibited specific adhesively bonded finger joints that, according to the authors, although "still in its infancy", hold an enormous potential regarding lower costs, higher stiffness, higher capacity and better fire resistance.

\subsection{Capacity prediction of timber structures}

Failure modes of structural timber elements and joints vary depending on member and joint geometry as well as material type and its associated failure modes. In tension and shear, timber essentially exhibits a linear elastic behaviour, and failure is marked by a brittle fracture Eberhardsteiner [17]. The constitutive behaviour of wood under multi-axial stress states has only been considered rarely [18, 19] and relatively little is known about the associated failure behaviour. Eberhardsteiner [17] experimentally determined the stressstrain behaviour of clear spruce wood under multi-axial loading and observed interactions between tension and shear strengths which were later micro-mechanically explained by Grosse and Rautenstrauch [20]. A number of failure criteria applicable to timber have been developed, and various in depth reviews were published, e.g. Kasal and Leichti [21]; a commonly applied criterion was proposed by Norris [22], see Eq. 1:

$$
\begin{aligned}
& \left(\frac{\sigma_{X}}{f_{X}}\right)^{2}-\left(\frac{\sigma_{X} \sigma_{Y}}{f_{X} f_{Y}}\right)+\left(\frac{\sigma_{Y}}{f_{Y}}\right)^{2}+\left(\frac{\tau_{X Y}}{f_{X Y}}\right)^{2}=1 \\
& \left(\frac{\sigma_{Y}}{f_{Y}}\right)^{2}-\left(\frac{\sigma_{Y} \sigma_{Z}}{f_{Y} f_{Z}}\right)+\left(\frac{\sigma_{Z}}{f_{Z}}\right)^{2}+\left(\frac{\tau_{Y Z}}{f_{Y Z}}\right)^{2}=1 \\
& \left(\frac{\sigma_{Z}}{f_{Z}}\right)^{2}-\left(\frac{\sigma_{Z} \sigma_{X}}{f_{Z} f_{X}}\right)+\left(\frac{\sigma_{X}}{f_{X}}\right)^{2}+\left(\frac{\tau_{Z X}}{f_{Z X}}\right)^{2}=1
\end{aligned}
$$


where $\sigma_{X}, \sigma_{Y}$, and $\sigma_{Z}$ are the normal, $\tau_{X Y}, \tau_{X Z}$, and $\tau_{Y Z}$ shear stresses, respectively and $f_{X}, f_{Y}, f_{Z}$, respectively $f_{X Y}, f_{X Z}$, and $f_{Y Z}$ are the material strength parameters.

The knowledge of the failure criterion has proved to not to be sufficient to predict joint capacities, since the mechanical strength of brittle materials, such as timber, exhibits size effect (the phenomena that strength decreases with increasing specimen size under the same test conditions). Three main types of size effects may be distinguished [23]: (i) a statistical size effect; (ii) an energetic size effect; and (iii) the possible size effect due to micro-cracks; some authors considering fractals as a possible explanation [24]. For brittle materials, like timber, statistically based size effects are adequately explained by the Weibull theory [25] which assumes that the cumulative survival probability $P_{\mathrm{S}}$ of a volume subjected to a non-uniform stress distribution is given by Eq. 2:

$P_{\mathrm{S}}=\exp \left[-\int_{V}\left(\frac{\sigma}{\sigma_{0}}\right)^{k} \mathrm{~d} V\right]$

where, $\sigma$ is the stress acting over a volume $V, \sigma_{0}$ is the characteristic stress or scale parameter and $k$ is the shape parameter that gives a measure of the strength variability, with low values of $k$ corresponding to a high variability in material. One consequence of Eq. 2 is that for two volumes $V_{1}$ and $V_{2}$ submitted to constant stresses $\sigma_{1}$ and $\sigma_{2}$ at failure, assuming equal probabilities of survival, the relationship given in Eq. 3, which allows for a straightforward implementation of size effects in numerical procedures, is obtained:

$\frac{\sigma_{1}}{\sigma_{2}}=\left(\frac{V_{2}}{V_{1}}\right)^{1 / k}$

Although there has been significant work on failure criteria development, existing criteria do not include size effects in timber under multi-axial stresses. Using Weibull theory to analyze components with stress concentrations, capacities can be considerably underpredicted [26]. Nevertheless, recognition of size effects is important when using conventional strength-based failure criteria as shown by Clouston et al. [27] who implemented Weibull theory into the Tsai-Wu failure criterion to assess size effects in Laminated Veneer Lumber.

Although increasingly being used for fibrous and anisotropic materials, such as fibre reinforced polymers [11], adhesive bonding, is not yet widely applied for timber structural elements. Before adhesive bonding can gain acceptance for such use, methods need to be disseminated that predict the joint capacity as a function of the material properties, the joint geometry and the type of loading. A prerequisite for the successful capacity prediction is the understanding of the stress-strain state in the joint, the latter being determined either analytically, e.g. Volkersen [28] or Goland and Reissner [29], or numerically (most commonly with the use of finite element analysis (FEA)). Contrary to analytical solutions, which are mostly restricted to idealized joints [30, 31], FEA permits the consideration of all relevant geometrical details as well as the actual material behaviour [32-34].

The capacity determination of joints exhibiting brittle failure can also be solved using fracture mechanics. Most commonly used are linear elastic fracture mechanics (LEFM), which require a pre-existing crack and often idealize the constitutive material behaviour. The generalised LEFM, e.g. [35] allows lifting the restrictions of the pre-existing cracks, and enables its application to arbitrary geometries. However, all methods derived from LEFM usually require an extensive and often tricky mechanical material characterisation; further, their implementation into actionable design routines is by far not straightforward.

\subsection{Objective}

The purpose of the article is to present experimental evidence that adhesively bonded joints of load bearing timber members can be successfully implemented in full size structures, herein on the example of trusses. Beyond this proof, the paper applies a straightforward dimensioning method that enable practitioners to safely dimension adhesively bonded timber structures for static short term loading.

\section{Experimental investigations}

\subsection{Experimental plan}

The experimental plan related on the structural performance of the adhesively bonded full-scale timber trusses were articulated on three levels:

Firstly, it was paramount to characterise the main constituent of the trusses, namely the timber. The 

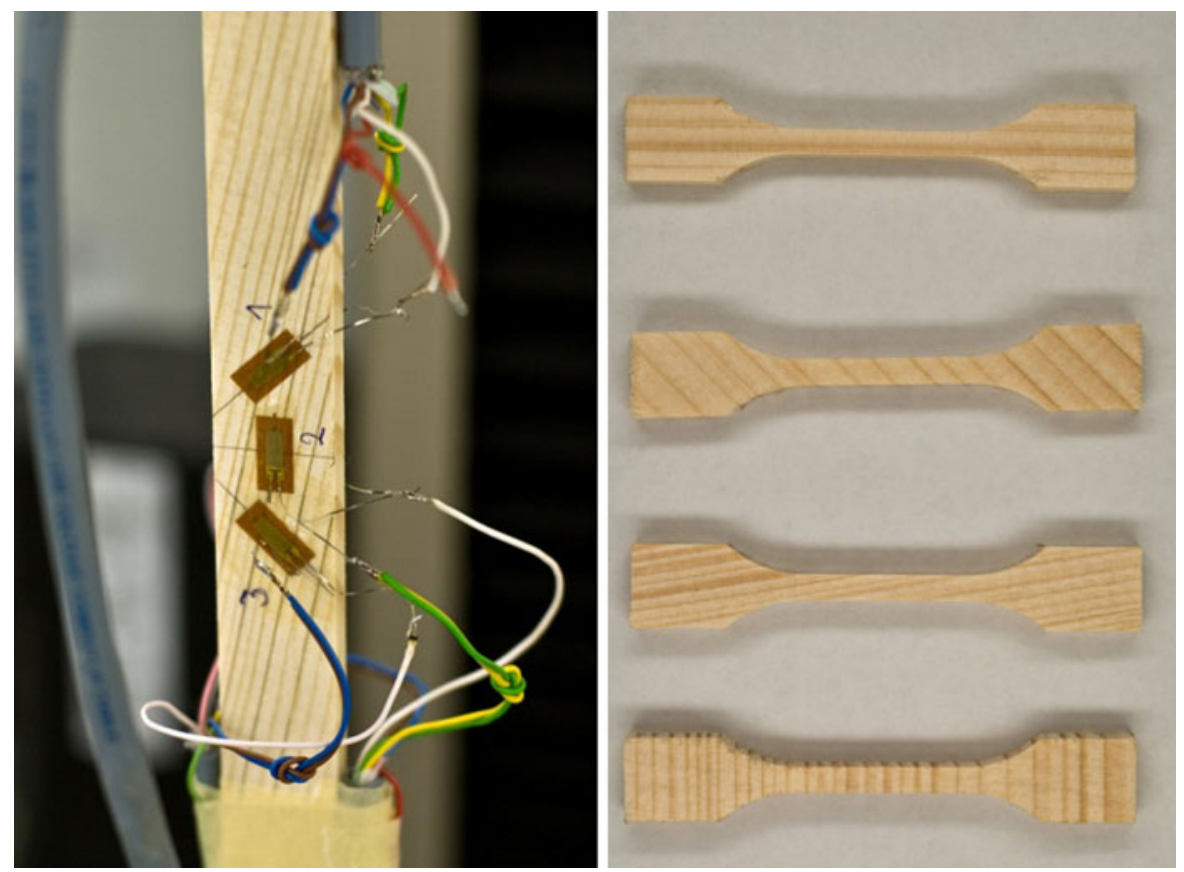

Fig. 2 Specimens to characterise the timber's mechanical properties

stress state in and around the adhesively bonded joints of such a complex system as the considered trusses has to be described as being multi-axial; thus, the corresponding material characterisation has to account for the influence of the interaction of stresses on the strength.

Secondly, the sole timber connection was characterised, giving valuable insights into the mechanical behaviour of this truss component. For this purpose, the influence of the embedded length of the applied sleet plates was experimentally determined, delivering data to benchmark the subsequent dimensioning method.

Thirdly, experimental investigations were carried out on full-scale timber trusses; two series, involving three samples each, were considered: (a) trusses using dowel type connections, and (b) trusses in which joints were achieved by means of adhesive bonding using a standard two-component epoxy adhesive.

\subsection{Experimental investigations on timber}

The timber species used was spruce (Picea Abies), representing the most used commercial species for timber construction in Central Europe. The material was conditioned to $12 \%$ moisture content prior to manufacturing of the specimens, and then again stored in constant climate until testing. The elastic properties, required for the subsequent numerical modelling, for which the material was assumed homogeneous and transverse isotropic, were determined on the specimens shown in Fig. 2 from the same timber batch that were used to produce the elements of the subsequent experiments. The strength parameters were determined on a large set of small sized samples that followed the geometrical specifications of ISO 527 (dog bone shape with reduced width in the centre). These samples were divided into groups exhibiting different orientations, $\alpha$, relatively to the grain, also shown in Fig. 2. Only those specimens that failed in the dog-bone neck were considered for the further investigations, the others were rejected. Four series of off-axis tests were performed: (i) $0^{\circ}$, involving solely $\sigma_{X}$ and delivering the axial strength parallel to the grain, $f_{X}$; (ii) $10^{\circ}$; (iii) $45^{\circ}$; and (iv) $90^{\circ}$, which only involves $\sigma_{Y}$, delivers the strength perpendicular to the grain, $f_{Y}$. Series (ii) and (iii) deliver results in which $\sigma_{X}, \sigma_{Y}$, and $\tau_{X Y}$ act simultaneously. The load, $P$, results in stresses in the principal material axis $(1,2)$ by transformation as follows: 
Table 1 Mechanical properties of the timber and the adhesive

\begin{tabular}{llllllllll}
\hline Material & $E_{x}(\mathrm{MPa})$ & $E_{y}(\mathrm{MPa})$ & $v_{x z}(-)$ & $v_{y z}(-)$ & $f_{x}=f_{0^{\circ}}(\mathrm{MPa})$ & $f_{y}=f_{z}=f_{90^{\circ}}(\mathrm{MPa})$ & $f_{x y}(\mathrm{MPa})$ & $f_{10^{\circ}}(\mathrm{MPa})$ & $f_{45^{\circ}}(\mathrm{MPa})$ \\
\hline Timber & 17,900 & 1,100 & 0.40 & 0.04 & 98.2 & 4.5 & 16.5 & 43.7 & 11.5 \\
Steel $^{\mathrm{a}}$ & 210,000 & & 0.3 & & 235 & & 135.6 & $\mathrm{c}$ & $\mathrm{c}$ \\
SikaDur330 $^{\mathrm{b}}$ & 4563 & & 0.3 & 39 & $\mathrm{c}$ & $\mathrm{c}$ & $\mathrm{c}$ \\
\hline
\end{tabular}

${ }^{a}$ Corresponding to grade S235 according to EC3

b Resulted from tension tests according to ENISO527-2

c Not determined

$\sigma_{1}=\sigma_{0} \cos ^{2} \alpha \sigma_{2}=\sigma_{0} \sin ^{2} \alpha \tau_{12}=\sigma_{0} \sin \alpha \cos \alpha$

where $\sigma_{0}=P / A, A$ being the cross-sectional area of the specimen, and $\alpha$ the off-axis orientation related to the grain. Assuming that the $\mathrm{n}$ sets previously defined will, on average, comply with (Eq. 1), it is an easy task to determine the shear strength, $f_{X Y}$ [36].

Table 1 summarizes the mechanical properties of the timber, which range are at the high end of the values stated in the literature [37], the difference is explained by the use of high quality almost defect free timber.

\subsection{Experimental investigations on joints}

In order to experimentally determine the strength of adhesively bonded joints between timber members and steel plates, quadratic timber sections $(75 \mathrm{~mm} \times$ $75 \mathrm{~mm})$ were slotted and steel plates $\left(t_{\mathrm{s}}=5 \mathrm{~mm}\right)$ were glued (adhesive layer thickness $t_{\mathrm{a}}=1 \mathrm{~mm}$, on both sides); the specimens are displayed in Figs. 3 and 4 . The materials used were the following: spruce, as characterised in Sect. 2.2; a two component cold curing epoxy adhesive, SikaDur330, which was characterised in a previous study to have a linear-elastic and brittle behaviour [38]; and common structural steel, grade S235 according to EC3.

The influence of the adhesive layer thickness on the strength of double lap joints composed of timber profiles was experimentally and numerically investigated by Tannert et al. [39]; the authors concluded that within the considered range, the adhesive layer thickness had only a small influence on the stress distribution and almost no influence on the joint capacity. Therefore, the sole parameter investigated was the embedded length, $L$, which was varied from 40 to $160 \mathrm{~mm}$, in steps of $40 \mathrm{~mm}$, thus leading to four distinct series labelled herein (BJ40) to (BJ160). For the purpose of comparison, an additional series was fabricated in which the

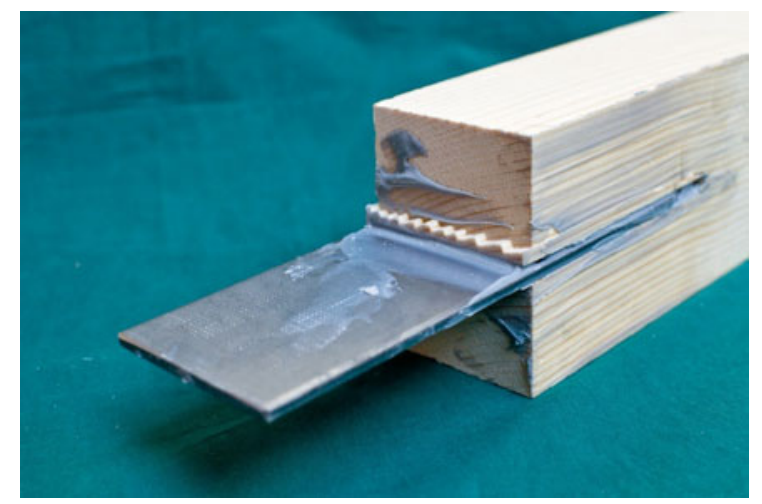

Fig. 3 A typical bonded timber-steel joint after testing

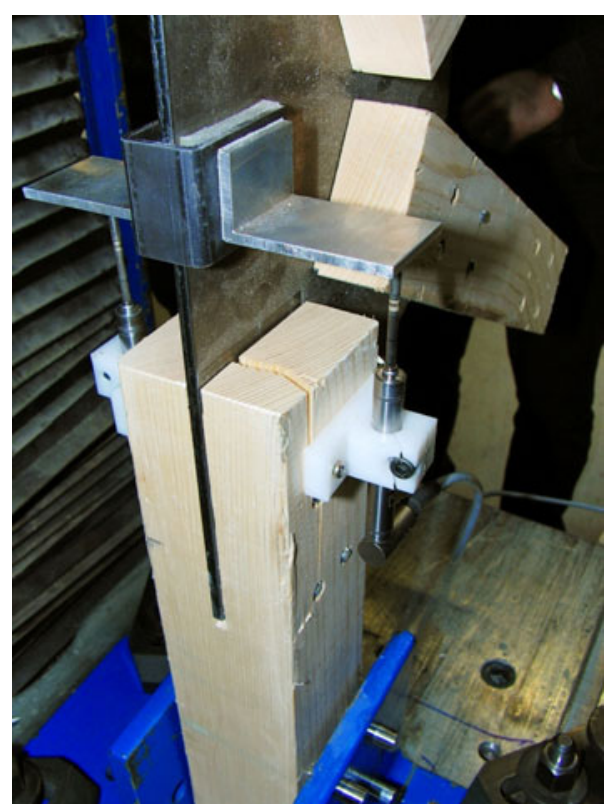

Fig. 4 A typical dowelled timber-steel joint after testing

connection was achieved by means of steel dowels (4Ø8 mm), subsequently labelled (DJ120). The number of dowels was chosen in such a way that the timber members and the doweled joints achieved the same 


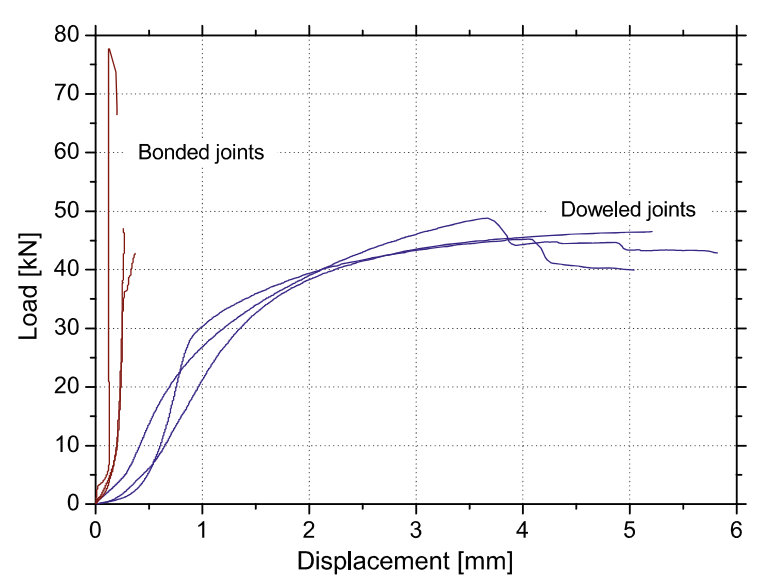

Fig. 5 Load-displacement curves of representative bonded timber-steel joints (embedment length $120 \mathrm{~mm}$ ) in comparison to dowelled timber joints

design load according to Eurocode 5. The dowel holes were predrilled with the same diameter as the dowel itself. Each series consisted of five specimens.

All tests were performed on a universal testing machine in displacement controlled traction $(1 \mathrm{~mm} /$ min) under controlled laboratory climate $\left(20^{\circ} \mathrm{C}\right.$, $65 \%$ relaitive humidity). The load-displacement was recorded up to failure, the ultimate load being labelled $F_{\text {EXP. }}$ The mechanical behaviour of all experimentally investigated series is best described by Fig. 5 that shows the load-displacement curves of representative BJ120 and DJ120 specimens: adhesively bonded connections clearly exhibit linear-elastic behaviour with a very brittle failure triggered inside the timber, indicated by Fig. 3, which represents a typical specimen after failure. The doweled connections on the other hand exhibit a less brittle behaviour, with much larger displacements, although it should not be confused with ductility; Fig. 4 depicts a representative specimen after failure.

The experimentally determined joint capacities $\left(F_{\text {EXP }}\right)$ are plotted against the embedment length in Fig. 6; Table 2 lists all joint capacities, defined by the average over each series and the corresponding standard deviation.

\subsection{Experimental investigations on full-scale trusses}

In order to investigate the suitability and practicability of bonded joints in a full scale context, two series of trusses with identical dimensions were fabricated:

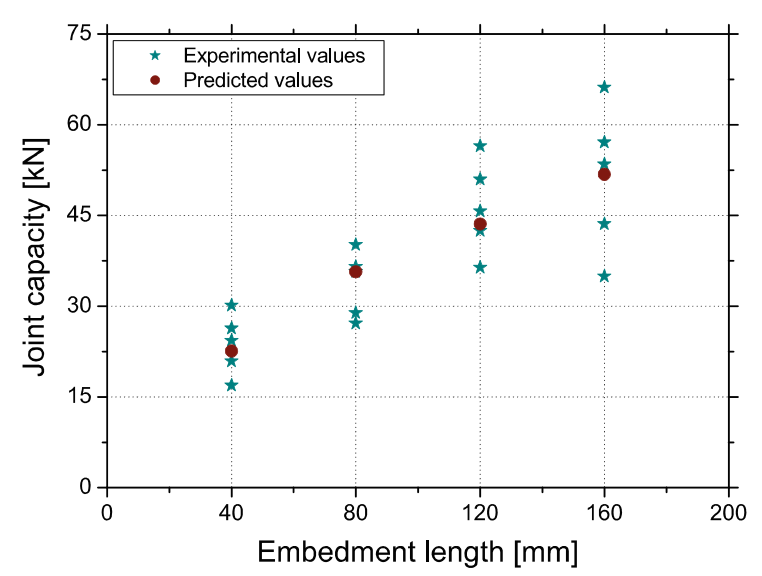

Fig. 6 Experimental and predicted capacities of the bonded joint versus embedment length

Table 2 Experimental results related to the joints and the trusses

\begin{tabular}{lllll}
\hline Series & $\begin{array}{l}F_{\text {EXP }}(\mathrm{kN}) \\
\text { Average }\end{array}$ & $\begin{array}{l}F_{\text {EXP }}(-) \\
\text { variance }\end{array}$ & $F_{\text {FEA }}(\mathrm{kN})$ & Accuracy (-) \\
\hline BJ40 & 23.7 & $21 \%$ & 22.6 & $+5 \%$ \\
BJ80 & 33.7 & $16 \%$ & 35.7 & $-6 \%$ \\
BJ120 & 46.4 & $17 \%$ & 43.6 & $+6 \%$ \\
BJ160 & 51.1 & $24 \%$ & 51.8 & $-1 \%$ \\
DJ120 & 27.8 & $10 \%$ & 27.0 & $+3 \%$ \\
BT & 62.9 & $13 \%$ & 63.9 & $+8 \%$ \\
DT & 44.9 & $14 \%$ & 41.5 & $-2 \%$ \\
\hline
\end{tabular}

- DT: trusses in which the joints between the members were achieved using steel plates $(t=5 \mathrm{~mm})$ and four steel dowels $(\varnothing 8 \mathrm{~mm})$ at each connection; and

- BT: trusses in which the joints between the members were achieved by the same steel plates as in DT, which subsequently was adhesively bonded.

All trusses were built up using identical square timber sections $75 \mathrm{~mm} \times 75 \mathrm{~mm}$ of spruce (Picea Abies).

The trusses (global dimensions and all upcoming node numbers are depicted in Fig. 7) spanned $4,200 \mathrm{~mm}$ at a height of $1,296 \mathrm{~mm}$. All trusses were simply supported on both ends and centrally loaded with a steel plate placed between the truss and the load actuator. Additional bracings ensured lateral stability, as shown in Fig. 8. 


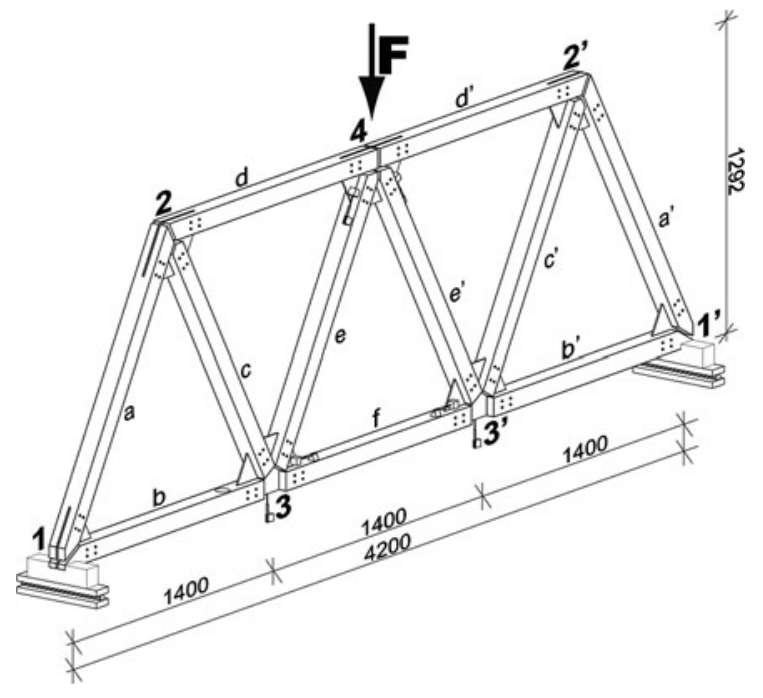

Fig. 7 Schematic truss representation, detailing dimensions (in $\mathrm{mm}$ ) and nomenclature

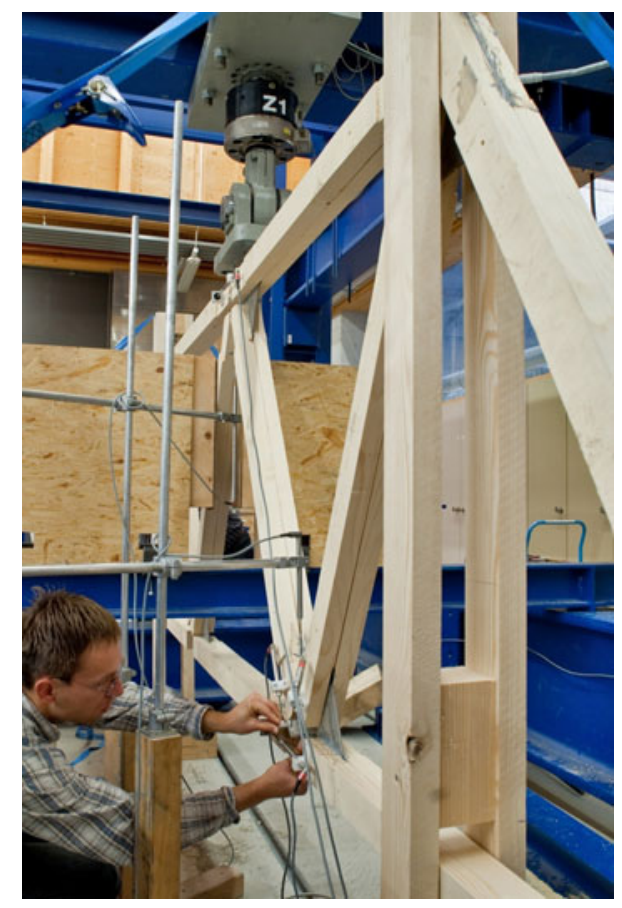

Fig. 8 A typical truss in test rig

To compare the stiffness of both types of trusses in the elastic range, which corresponds to a direct comparison in serviceability limit state (SLS), a loadcontrolled loop was run between 10 and $30 \mathrm{kN}$. Following, a displacement controlled load $(3 \mathrm{~mm} /$ min) was applied up to the collapse of the specimens. The instrumentation consisted of a series of calibrated transducers for measuring the load-displacement behaviour at several points of the truss, as well as the relative displacement at the truss joints. In order to compensate for the relative flexibility of the steel frame, the deformation of the bearings were measured, all subsequently presented data was corrected accordingly.

Additionally, for one representative truss of each series, strain gauges were positioned on the inner and outer faces of the diagonal (a), as shown in Fig. 7, at a distance of $500 \mathrm{~mm}$ from the supports; the resulting strain measurements allowed estimating how much the truss members were bent due to the joint stiffness. The bending restraint is numerically best expressed by the comparison of bending moments, $M$, relatively to the normal forces, $N$, using the following sets of Equations:

$$
\begin{aligned}
& M=\frac{\varepsilon_{2}-\varepsilon_{1} a^{3} E_{x}}{2} 6 \\
& N=\frac{\varepsilon_{2}+\varepsilon_{1}}{2} a^{2} E_{x}
\end{aligned}
$$

where $\varepsilon_{1}$ and $\varepsilon_{2}$ represent the measured axial strains at the two opposites sides of the timber members, $a$ the dimensions of the square timber members and $E_{X}$ the axial Young's modulus of the timber.

The load displacement curves of the adhesively bonded trusses were almost perfectly linear, up to failure, as shown in Fig. 9; in contrast, the doweled trusses behaved much softer, allowing for much higher deformations at matching loads. A significant part of this overall deformation is clearly attributable to the fact that doweled connections only start to transmit forces after large relative deformations.

Failure of the bonded trusses, occurred by splitting just below the end of the bond, shown in Fig. 10, in all cases failure triggered by a crack that developed from the surface. Figure 11 shows a typical steel plate after the test, clearly indicating fibres that remained bonded to the steel plate. Failure of the doweled truss occurred by the brittle splitting of the timber, as shown in Fig. 12.

The strain gauge measurements were transformed into normal forces and bending moment using Eq. 4; Fig. 13 shows that the normal force in the truss element increases linearly with the applied external force. No clear correlation between bending moment and external force seems to exist, due to the fact that 


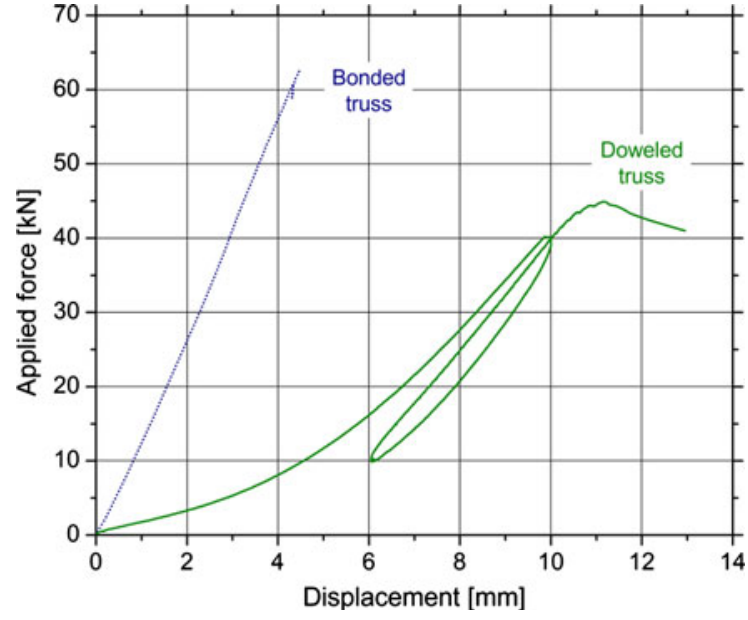

Fig. 9 Load displacement curves of a typical bonded and doweled truss

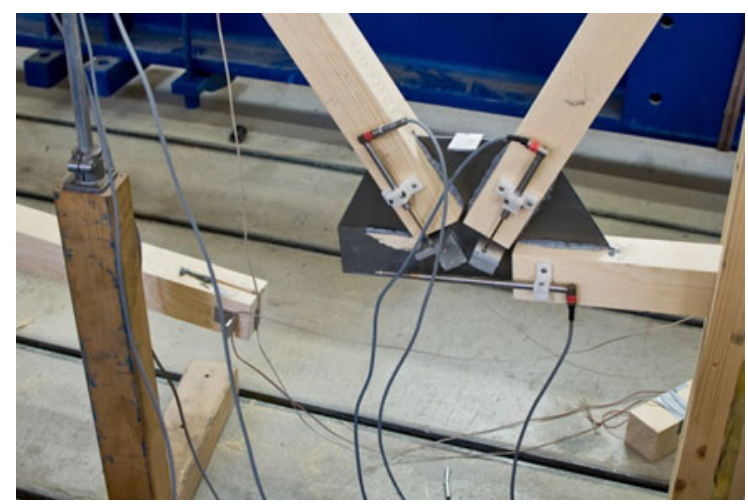

Fig. 10 Detail of failure of a typical bonded truss

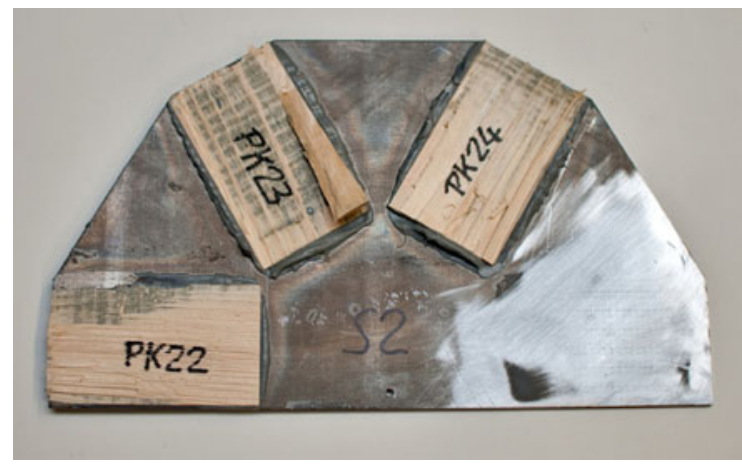

Fig. 11 Detail of the steel plate of a typical bonded truss after testing (brittle rupture of timber)

bending moments are determined as the difference of two readings of similar magnitude, which are then significantly amplified. Nevertheless, it is clearly

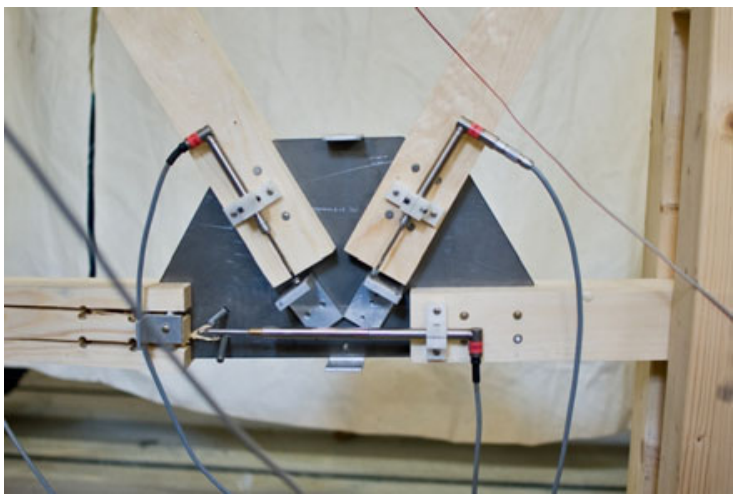

Fig. 12 Detail of failure of a typical doweled truss (splitting of timber at one truss member)

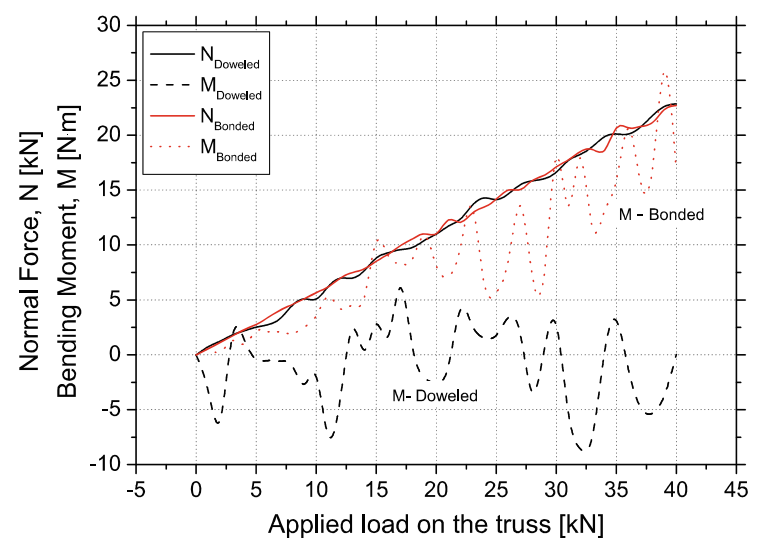

Fig. 13 Normal forces and bending moment in member (c) for typical trusses

shown that bonded joints lead to significantly higher bending moments in the corresponding truss members, compared to the doweled joints.

Further experimental results, averaged for each series, can be summarized as follows:

- Considering the deformation encountered during the loop 10-30 kN, it can be shown that the bonded trusses exhibit a "stiffness" of around $15.4 \mathrm{kN} / \mathrm{mm}$, while their doweled counterparts range at $5.6 \mathrm{kN} / \mathrm{mm}$; bonded trusses are roughly three times stiffer than the doweled;

- The relative horizontal displacement of a truss member in traction, see Fig. 14, measured on diagonal c'(Fig. 7), at the same load step of $40 \mathrm{kN}$, indicate a value of $0.02 \mathrm{~mm}$ for the bonded truss, and $0.54 \mathrm{~mm}$ for the doweled one: the doweled joint exhibits therefore an approximately 30 times higher deformation; 


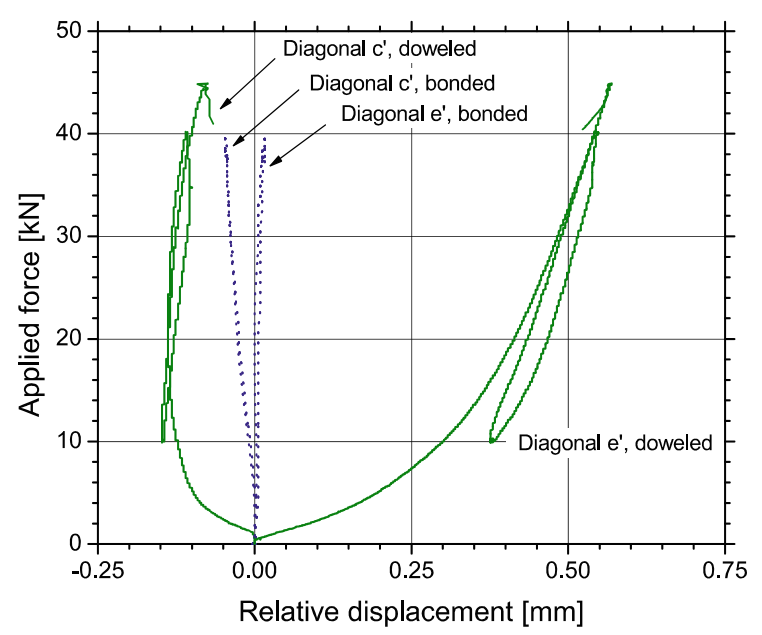

Fig. 14 Relative horizontal displacements on truss members (c) and (e) for typical trusses

- The relative displacement of a truss member in compression, also shown in Fig. 14, measured on the diagonal e' (Fig. 7), at a reference load of $40 \mathrm{kN}$, differs by approx. $300 \%(-0.32 \mathrm{~mm}$ for the doweled, $-0.05 \mathrm{~mm}$ for the bonded);

- At a comparable load level of $40 \mathrm{kN}$, the doweled trusses deformed by an average of around $9.8 \mathrm{~mm}$, while their bonded counterparts experienced deformations of around $2.3 \mathrm{~mm}$;

- On average, the bonded trusses failed at a load of $62.9 \mathrm{kN}$, while the doweled ones failed under $44.9 \mathrm{kN}$, indicating that the bonded trusses exhibit a strength higher by around $40 \%$ compared to the doweled, while failure was more brittle;

- Significant bending moments occur in the adhesively bonded trusses, as indicated by the readings of the strain gauges. This is best represented by transforming the strains into the corresponding normal forces and bending moments according to Eq. 5.

\section{Modelling}

\subsection{Modelling of the timber}

As adhesively bonded joints fail under a combination of stresses, it is necessary to extend the concept of the Weibull distribution towards stresses acting simultaneously. For this purpose, it was decided to consider the Norris criterion Eq. 1 as a stress operator, $\sigma_{F}$, defined by Eq. 6:

$$
\sigma_{F}^{2}=\left(\frac{\sigma_{X}}{f_{X}}\right)^{2}-\left(\frac{\sigma_{X} \sigma_{Y}}{f_{X} f_{Y}}\right)+\left(\frac{\sigma_{Y}}{f_{Y}}\right)^{2}+\left(\frac{\tau_{X Y}}{f_{X Y}}\right)^{2}
$$

In the latter definition, $\sigma_{F}^{2}=1$ defines failure. To consider size effects, it is necessary to determine the Weibull parameters, i.e. $k$ and $\sigma_{0}$. A regression procedure on the probability distribution of the $\sigma_{F^{-}}^{2}$ values corresponding to all 160 specimens tested for the brittle material properties were used; the Weibull modulus was found to equal $k=3.717$, while $\sigma_{F, 0}=1.124$.

\subsection{Modelling of the joints}

To assist the interpretation of the experimental results obtained, the adhesively bonded joints were modelled using the finite element program ANSYS (v12). Timber is an anisotropic and inhomogeneous material, but for simplicity in modelling, the material was assumed to be homogeneous and transverse isotropic with identical properties in radial and tangential directions. The longitudinal direction is referred to as parallel to grain (herein defined by the subscript $X$ ), while the combined radial and tangential directions are referred to as perpendicular to grain (subscript $Y$ ). Symmetry conditions were used to reduce the modelling to one quarter. The material properties used for the FEA are listed in Table 1. 20-node elements were applied; the mesh size was set to $10 \mathrm{~mm}$ for the timber part, $5 \mathrm{~mm}$ for the steel and for the adhesive, with a mesh refinement at the joints. Concerning the bonded connections, the adhesive layer was modelled as being fully connected with the timber, not allowing for any relative slip, corresponding to the experimental observations. For the doweled joints, the exact geometry of the connection was modelled, including the position and dimensions of the dowels (represented in Fig. 15, which represents half of the connection, since symmetry has been exploited). The contact between the dowels and the timber has been modelled using target and contact surface-to-surface elements. Plastic behaviour of the dowels was not considered in the FEA as it adds no information to the subsequent capacity predictions under brittle failure. Figures 16 and 17 show the development of transverse stresses, $\sigma_{Y}$, and shear stresses, $\tau_{X Y}$, along the embedment of the bonded 
Fig. 15 FEA detail of the doweled truss (at the connection)

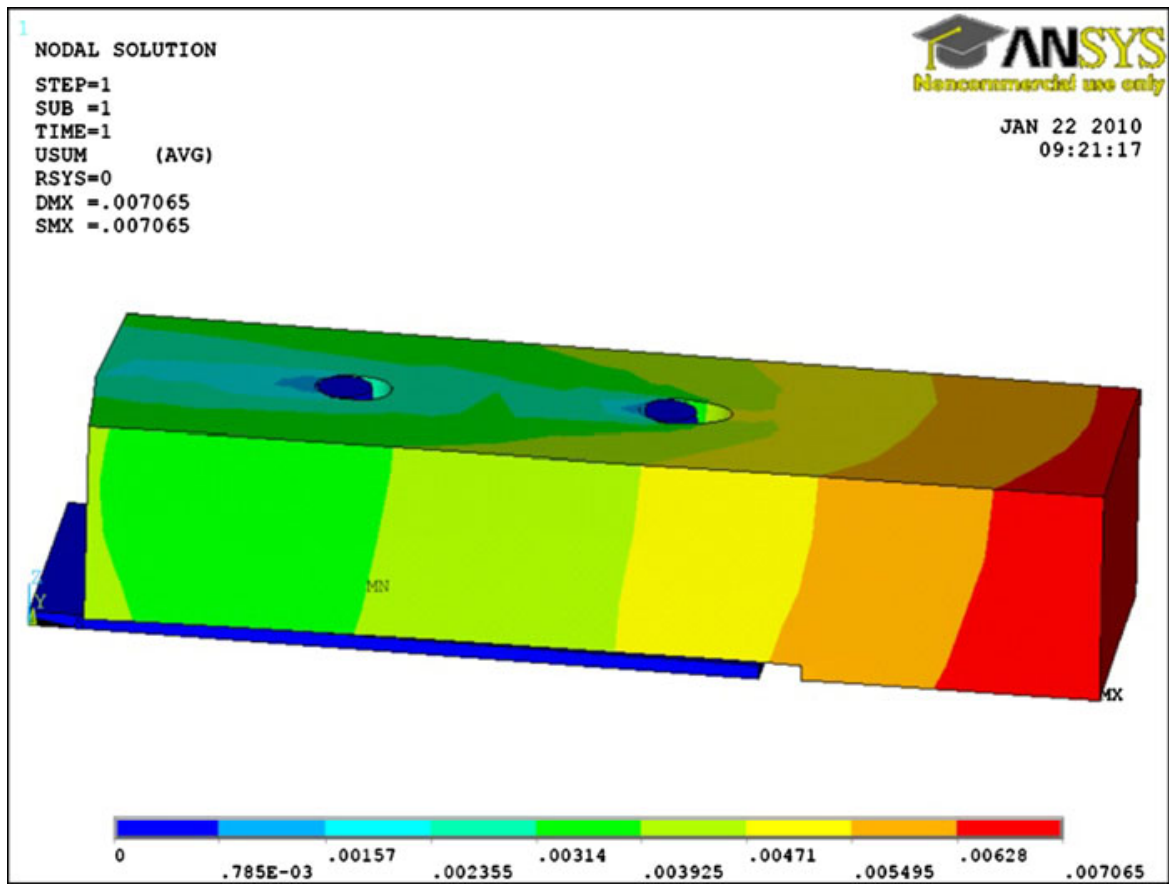

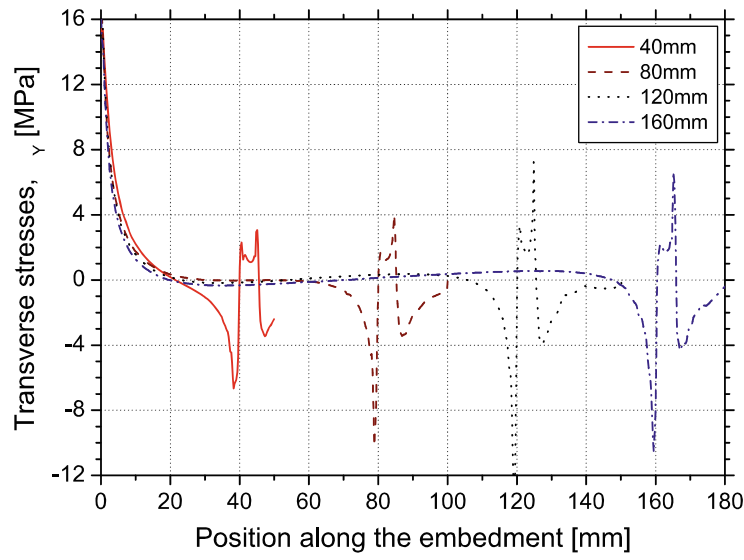

Fig. 16 Transverse stresses acting on the bonded timber-steel joint

joints, respectively, herein at the Gauss points of the interface between the timber and the adhesive at failure load.

The stress peaks, that are expected to arise according to the analytical formulae and FEA discussed in the introduction are clearly visible. The shear stresses peak at the end of the embedment to values close or beyond the resistance of timber, which was found to be $f_{X Y}=16.5 \mathrm{MPa}$ : for the overlap length of $40 \mathrm{~mm}$ the

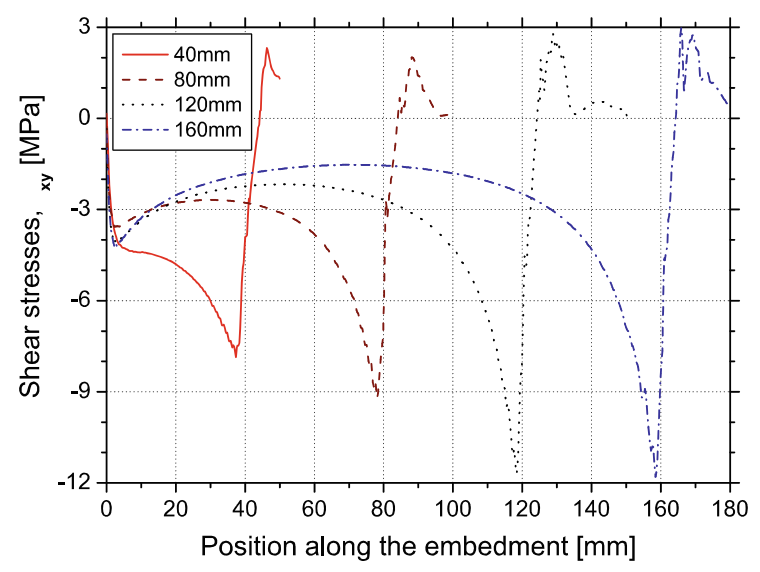

Fig. 17 Shear stresses acting on the bonded timber-steel joint

peaks amounts to $15.8 \mathrm{MPa}$ at failure, while it is $23.9 \mathrm{MPa}$ for the $160 \mathrm{~mm}$ embedment. Similarly, at the failure of the respective specimens, the transverse stresses, which are compressive at the beginning of the embedment, reach at the end of the embedment, where they act in tension, values of 6.7 MPa for the specimen with an embedment of $40 \mathrm{~mm}$ up to $10.3 \mathrm{MPa}$ for the longest embedment tested, $160 \mathrm{~mm}$. Once again, these values far exceed the material's resistance, which was found to be $f_{Y}=4.5 \mathrm{MPa}$. 


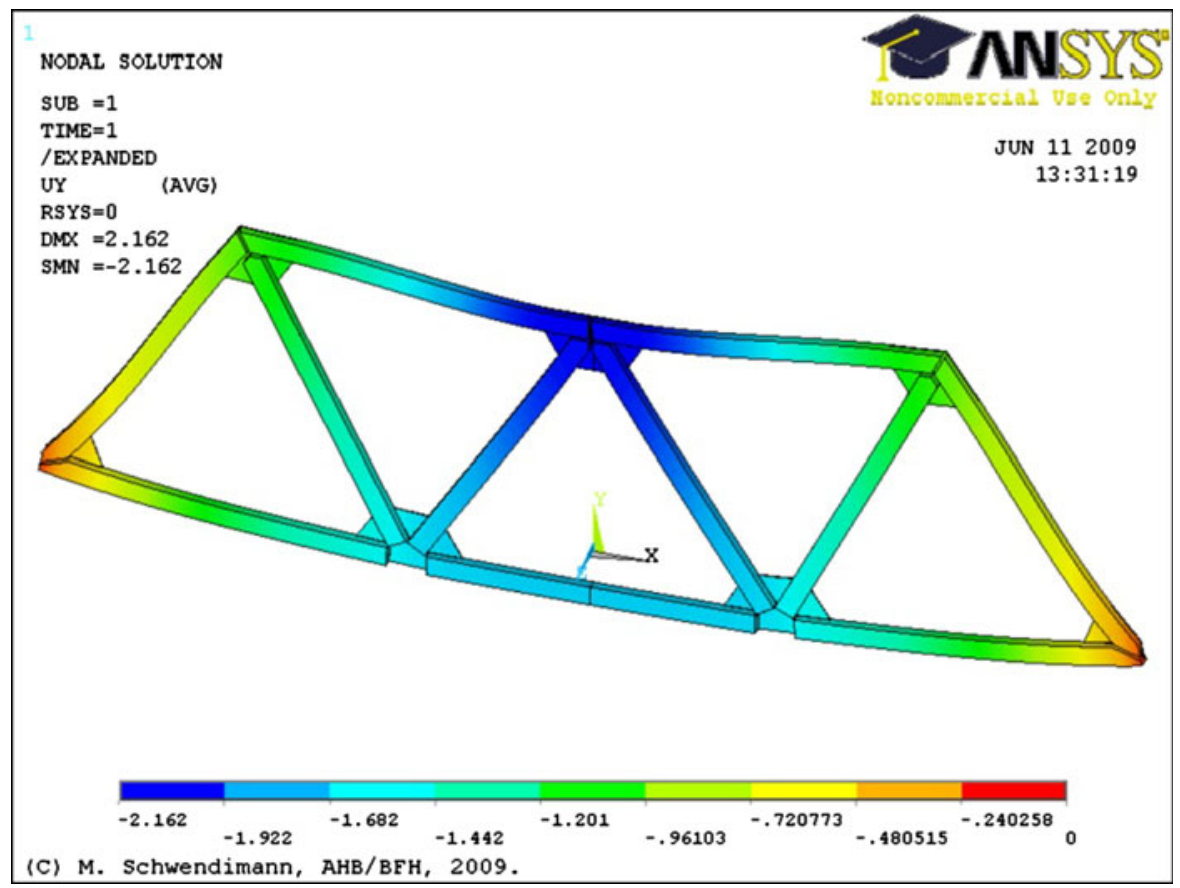

Fig. 18 FEA model of the bonded truss

\subsection{Modelling of the truss}

Coordinate systems were locally defined at the level of all truss members, to make the main axis coincide with the orthotropic material properties. Figure 18 shows the generated numerical model. Because the joints are symmetric about the $X$ and $Z$ direction, symmetry conditions were used to reduce the modelling to one quarter. The timber and the contact between the dowels and the timber has been modelled using the same elements as for the model of the joints; while the mesh was slightly coarser with $10 \mathrm{~mm}$ for the timber part, and $5 \mathrm{~mm}$ for the steel and for the adhesive. Concerning the bonded connections, the adhesive layer has been modelled as being fully connected with the timber. Using FEA, and at a reference load of $40 \mathrm{kN}$, the vertical displacement of the bonded truss at node 4 was determined to $2.16 \mathrm{~mm}$; this value being in very good agreement compared to the $2.27 \mathrm{~mm}$ obtained experimentally.

\subsection{Capacity prediction}

If the whole bonded joint is idealized as being constituted by $\mathrm{n}$ elements, its survival depends on simultaneous non-failure of all elements. Consequently, if each constituent element $i$, with a volume $V_{i}$ is subjected to $\sigma_{F, i}$, the global probability of survival is given by Eq. 7:

$$
\begin{aligned}
P_{\mathrm{S}} & =\prod_{i=1}^{n} \exp \left[-\frac{V_{i}}{V_{0}} \cdot\left(\frac{\sigma_{\mathrm{F}, i}}{\sigma_{\mathrm{F}, 0}}\right)^{k}\right] \\
& =\exp \sum_{i=1}^{n}\left[-\frac{V_{i}}{V_{0}} \cdot\left(\frac{\sigma_{\mathrm{F}, i}}{\sigma_{\mathrm{F}, 0}}\right)^{k}\right]
\end{aligned}
$$

where $V_{\mathrm{i}}$ are the volumes of the considered finite elements, $V_{0}$ is the reference volume of the small samples (restricted to the stresses zone between the necks, herein $500 \mathrm{~mm}^{3}$ ), $\sigma_{F, i}$ is given by (Eq. 6). In this research, the stresses needed to formulate $\sigma_{F}$, were gathered using the FEA models described in Sects. 3.4 and 3.5. It was previously shown that this approach is independent of mesh size, once a sufficiently accurate mesh is used [40]. Thus, after having determined all stresses, element by element, all $\sigma_{F, i}$ are computed using a spreadsheet, and eventually the corresponding probability of failure, $P_{\mathrm{S}}$, associated to each element. The global failure is thus defined as the load level, $F_{\mathrm{FEA}}$, for which Eq. 7 delivers a global probability of survival, $P_{\mathrm{S}}$, equal to $50 \%$. To determine a strength value used by practitioners for design purposes, the strength value corresponding to a probability of failure of $5 \%$ can also be calculated. In the present research, 
however, the sample size did not justify calculating such values.

The probabilistic model yields, for the joints of all series (i.e. BJ40-BJ160 and DJ120), the capacities listed in Table 2, where they are directly compared to the corresponding experimental values $\left(F_{\text {EXP }}\right)$. It clearly appears that joint capacity increase with the embedment length, but that this increase tends to flatten, indicating an upper limit, beyond which no capacity increase should be expected. The capacities of the doweled joints, if comparing it with a bonded joint of similar constructive size, is substantially lower, herein by around $40 \%$.

The probabilistic method delivers a capacity of $63.9 \mathrm{kN}$ for the bonded truss, while for the doweled truss, an average capacity of $41.5 \mathrm{kN}$ was numerically determined.

\section{Discussion}

\subsection{Experimental results}

The suggested material strength determination, i.e. using the off-axis small-scale specimens, offers a practical alternative to much more complex setups, since the manufacturing of the dog-done shaped specimens can be performed using CNC, allowing for large series of identical samples.

Failure of both doweled and bonded joints, and subsequently also the trusses built-up thereof, was brittle; even if the doweled trusses did not fail in the same "catastrophic" way the bonded ones did. However, this difference in perception is mainly due to the huge difference of stiffness between both types of trusses combined with the fact that the load was displacement controlled. In a load controlled, real-case situation, both would simply fail, and the doweled truss would not exhibit any kind of pseudo-ductile behaviour. If directly comparing joints with similar constructive size, i.e. the specimens of series BJ120, with the corresponding doweled joints, DJ, it becomes evident that adhesively bonded connections outperform the mechanical connectors in both strength (by around $40 \%$ ) and stiffness (by more than $300 \%$ !).

The experimental results also showed that the bonded trusses are much stiffer; in a design context in which control of deformation is paramount, this is clearly an advantage. Similarly, the bonded trusses outperform their doweled counterparts by around $40 \%$, which is similar to the ratio found on the joints. A large part of the increased stiffness is due to the fact that bonded connections do not need any relative slip to start transmitting forces, as it is the case for dowels; besides this effect, it ought to be noticed that the bonded connections do also lead to a restraint at the truss' nodes, which leads to bending moments acting positively on reducing the deformation, as it has been shown by the strain gauge measurements displayed in Fig. 13 and discussed in Sect. 3.

\subsection{Numerical results}

The numerical results were in fair accordance with the experimental values, which legitimately validated it. The FEA allowed determining the stress-strain state all over the structure, which is a prerequisite of the subsequent strength prediction, and clearly shows that considering a stress based dimensioning method, all specimens would not have survived their respective stress states. This clearly shows, without event taking into consideration the fact that simultaneously acting stresses lead to premature collapse, that a stress based dimensioning method is not able to handle the issue related to huge stress peaks. A similar observation can be drawn from considering the stress pattern at the dowels: Fig. 19 shows the axial stresses, $\sigma_{X}$, acting along the planes defined by the dowels; that the load transfer induced by the mechanical fasteners leads to the generation of stress peaks of such magnitude (herein, at failure, $\sigma_{X}$ peaks at a value of $94.5 \mathrm{MPa}$ ),

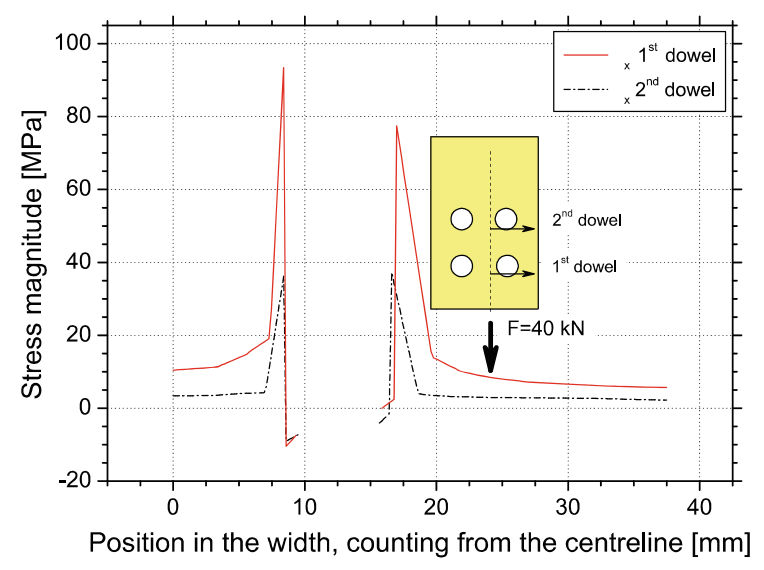

Fig. 19 Typical stress pattern around a dowel, for a doweled timber joint 
exceeding the material's resistance. It would thus have been impossible to determine the stresses at the joints using alternative methods, e.g. a simple truss calculation. The numerical modelling shows that, using modern FE software packages, and correctly implementing the orthotropic material properties of timber, it is relatively straightforward to achieve an accurate description of complex systems, as the investigated joints and trusses.

\subsection{Probabilistic capacity prediction}

The probabilistic method allowed considering the locally arising stress concentrations at the joints, which determine the truss' capacity. The probabilistic methods, with the implementation of size-effects, allowed accurately handling the issue of stress peaks arising at the joints, both doweled and bonded. The implementation of the probabilistic method resulted in accurate predictions of the capacity of all investigated systems:

- The bonded joints, for which prediction accuracy below $6 \%$ has been achieved;

- The doweled joints, whit a capacity prediction accuracy of $3 \%$;

- The two types of trusses, yielding in predictions as accurate as $8 \%$ for the doweled, and $2 \%$ for the bonded truss.

\subsection{Practical considerations}

All trusses were fabricated under laboratory conditions with controlled environment and under strict compliance to adhesive use regulations, as defined by the manufacturers. As with any adhesively bonded products, also trusses should be produced only by certified and controlled companies that have the proven expertise. One of the advantages of glued joints is their better fire protection, which at first sight seems contradictory since adhesives lose most of their mechanical properties beyond their respective glass transition temperature, but can be explained by the fact that the bonded surfaces lie protected by the timber which effectively insulates them. Further consideration as to what are the most suitable methods to protect the steel, e.g. coatings, were outside the scope of the presented research. The research also focused purely on static short term loading, the behaviour of adhesively bonded timber joints under long term and variable loading conditions is of extreme practical importance; further research will investigate these aspects.

\section{Conclusions}

The investigations presented herein show that, rather than being a purely academic topic, adhesively bonding as a mean of connecting load bearing elements holds the potential to unleash new architectural expression and structural performance in timber building and construction.

Material characterisation on small clear specimens allowed determining the mechanical properties of the timber, which were used as input parameters for FEA. The validity of the numerical modelling, for both truss types, was subsequently assessed by direct comparison with the experimental results.

The capacity of adhesively bonded connections composed of timber members and a steel plate were experimentally investigated; the capacity of bonded joints is higher that the one of doweled joints, if compared at similar sizes; this capacity increases with the embedment length, with a tendency to achieve a plateau at an embedment length of around $120 \mathrm{~mm}$. The scattering of the experimental values of the scattering is comparable to the one measured on doweled connections.

The experimental and numerical results on doweled and adhesively bonded timber trusses allow for a direct comparison of the two radically different joining methods. The adhesively bonded trusses achieved a significantly higher failure load compared to the mechanically connected truss.

Finally, a probabilistic design method, based on a realistic multi-axial failure criterion was implemented and yielded very good agreement when compared to the experimental results on both the bonded joints and the full-scale trusses.

\section{References}

1. Ban S, McQuaid M (2003) Shigeru Ban. Phaidon, Berlin, ISBN-10:0714841943

2. Buri H, Weinand Y (2008) ORIGAMI—folded plate structures architecture. In: Proceedings of the 10th WCTE, Miyazaki, Japan 
3. Weinand Y (2009) Innovative timber constructions. Int J Shell Spat Struct 50:111-120

4. Peters TF (1996) Building the nineteenth century. The MIT Press, Cambridge

5. Peters TF (2000) Technological thought is design's operative method, from perspecta31: reading structures. The MIT Press, Cambridge

6. Thelandersson S (1995) Serviceability limit statesdeformations. In: Timber engineering STEP 1. Centrum Hout, pp A17/1-A17/8

7. Broughton JG, Hutchinson AR (2001) Adhesive systems for structural connections in timber. Int J Adhes Adhes 21: $177-186$

8. Moss CJ (1946) Aeronautical engineering-bonding with Redux. The Aeroplane No. 329

9. Farshad M, Isfahanian D (1978) Iranian plateau-the homeland of original truss structures. J Am Orien Soc 98: 248-250

10. Müller A (2009) Grubenmanns Brücken. Tec21 135:26-31

11. Lewandoski J et al (2006) Historic American roof trusses. Timber Framers Guild, ISBN-10:0970664346

12. Navier CLMH (1838) Résumé des leçons données à l'Ecole des Ponts et Chaussées sur l'application de la mécanique à l'établissement des constructions et des machines, 2nd edn. Carilian-Goeury, Paris

13. Michon C (1848) Instructions sur la résistance des matériaux suivie d'applications aux pièces droites et aux fermes de charpentes des bâtiments. Ecole d'application de l'artillerie et du génie, Metz

14. Nelson LH (1996) Early wooden truss connections vs. wood shrinkage: from mortise-and-tenon joints to bolted connections. APT Bull 27:11-23

15. Sparks SP (2005) Evaluation of built-up timber trusses in late-nineteenth-and early-twentieth-century buildings. APT Bul 36:35-43

16. Poutanen T, Ovazza C (2010) Glued timber trusses. In: Proceedings of the 11th WCTE, Riva del Garda

17. Eberhardsteiner J (2002) Mechanisches Verhalten von Fichtenholz-Experimentelle Bestimmung der biaxialen Festigkeitseigenschaften. Springer, Vienna

18. Spengler R (1986) Festigkeitsverhalten von Brettelementen aus Fichte unter zweiachsiger Beanspruchung. Report 68098450340. Technical University Munich

19. Hemmer K (1984) Versagensarten des Holzes der Weisstanne unter mehrachsiger Beanspruchung. Dissertation, Universität Karlsruhe

20. Grosse M, Rautenstrauch K (2004) Numerical modelling of timber and fasteners used in timber-concrete-composite constructions. In: Proceedings of CIB-W18, Edinburgh, Scotland

21. Kasal B, Leichti RJ (2005) State of the art in multiaxial phenomenological failure criteria for wood members. Prog Struct Eng Mater 7:3-13

22. Norris CB (1962) Strength of orthotropic materials subjected to combined stresses. Report No.1816, Forest Products Laboratory, Madison
23. Bažant ZP (2005) Scaling of structural strength. Elsevier, London

24. Carpinteri A, Puzzi S (2009) The fractal-statistical approach to the size-scale effects on material strength and toughness. Prob Eng Mech 24:75-83

25. Weibull W (1939) A statistical theory of strength of materials. In: Proceedings of the royal Swedish institute, Research No.151, Stockholm

26. Smith I, Landis E, Gong M (2003) Fracture and fatigue in wood. Wiley, Chichester

27. Clouston P, Lam F, Barrett JD (1998) Incorporating size effects in the Tsai-Wu strength theory for Douglas-fir laminated veneer. Wood Sci Technol 32:215-226

28. Volkersen O (1965) Recherches sur la théorie des assemblages collés. Constr Metall 4:3-13

29. Goland M, Reissner E (1944) The stresses in cemented joints. J. Appl Mech A17-A27

30. Da Silva LFM, Das Neves PJC, Adams RD, Spelt JK (2009) Analytical models of adhesively bonded jointspart I: literature survey. Int J Adhes Adhes 29:319-330

31. Da Silva LFM, Das Neves PJC, Adams RD, Wang A, Spelt JK (2009) Analytical models of adhesively bonded jointspart II: comparative study. Int J Adhes Adhes 29:331-341

32. Adams RD (1987) Theoretical stress analysis of adhesively bonded joints. In: Matthews FL (ed) Joining fibre-reinforced plastics, Elsevier Applied Science, Essex

33. Keller T, Vallée T (2005) Adhesively bonded lap joints from pultruded GFRP profiles part I: stress-strain analysis and failure modes. Composites B 36:331-340

34. Tsai MY, Morton J (1994) An evaluation of analytical and numerical solutions to the single-lap joint. Int J Solids Struct 31:2537-2563

35. Serrano E, Gustafsson PJ (2006) Fracture mechanics in timber engineering - strength analyses of components and joints. Mater Struct 40:87-96

36. Xavier JC, Garrido NM, Oliveira M, Morais JL, Camanho PP, Pierron F (2004) A comparison between the Iosipescu and off-axis shear test methods for the characterization of Pinus Pinaster Ait. Compos A Appl Sci Manuf 35:827-840

37. Green DW, Winandy JE, Kretschmann DE (1999) Mechanical properties of wood. In: Wood handbook-wood as an engineering material. Forest Products Laboratory, Madison

38. Vallée T, Correia JR, Keller T (2006) Probabilistic strength prediction for double lap joints composed of pultruded GFRP profiles-part II: strength prediction. Comput Sci Technol 66:1915-1930

39. Tannert T, Hehl S, Vallée T (2010) Bemessung von geklebten Anschlüssen im Holzbau. Bautechnik 87:623-629

40. Tannert T, Lam F, Vallée T (2010) Strength prediction for rounded dovetail connections considering size effects. ASCE J Eng Mech 136:358-366 